\title{
Discrete Dynamical Analysis of Euler Scheme for Harvested Predator-Prey Model with Ratio- Dependent Response Function and Prey Refuge
}

\author{
Abdul Hadi \\ Departement of Informatics \\ Institut Teknologi dan Bisnis Asia \\ Malang, Indonesia \\ hadi@asia.ac.id
}

\author{
Siti Nurul Afiyah \\ Departement of Informatics \\ Institut Teknologi dan Bisnis Asia \\ Malang, Indonesia \\ noeroelafy@gmail.com
}

\author{
Vivi Aida Fitria \\ Departement of Informatics \\ Institut Teknologi dan Bisnis Asia \\ Malang, Indonesia \\ viviaidafitria@gmail.com
}

\begin{abstract}
In this research, Euler method is applied to discretize a harvested predator prey model with ratiodependent response function and prey refuge. The existence and stability of fixed points has been analyzed. Stability of each fixed point shown that the fixed points are stable for small size of time step. Such dynamical properties are also confirmed by numerical simulations.
\end{abstract}

Keywords-Dynamical Analysis, Discrete, Euler, Harvested Predator-Prey Model, Ratio-Dependent Response Function, Prey Refuge

\section{INTRODUCTION}

The predator-prey model is firstly introduced by LotkaVoltera which has been heavily modified by several researchers $[1,2,3]$. This is adapted based on the problems that occur in the predator-prey ecosystem. Lenzini and Rebaza [4] did a research on the predator-prey dynamic behavior by non-constant harvesting of predators by using a ratio-dependent response function, in which a predator function depends on both prey and predatory density. Furthermore Ilmiah [5] modified Kar's [6] model about predator-prey harvesting model by including prey protection with Holling Type II response function and model from Lenzini and Rebaza. Ilmiah modified it by adding prey refuge.

In this research, we use Euler method to discretize Ilmiah's model. Though, discrete models have a richer behavioural dynamic compared to continuous models [7]. However, it has disadvantaged that divergent approximation may be obtained. Hence, step-size plays an important role to avoid inconsistency [8]. Therefore in this study, Ilmiah's model will be constructed to be a discrete model. The numerical approach to convert the continuous model to the discrete model in this study is using the Euler scheme.

Furthermore, the fixed points, terms of existence, and stability of fixed points will be investigated.

In this research, harvested predator-prey model with ratio-dependent response function and prey refuge was discretized using the Euler method and resulting in the following discrete form of equation:

$$
\begin{aligned}
& x_{n+1}=x_{n}+h x_{n}\left(\left(1-x_{n}\right)-\frac{a(1-m) x_{n} y_{n}}{y_{n}+(1-m) x_{n}}-h_{1}\right)=f\left(x_{n}, y_{n}\right) \\
& y_{n+1}=y_{n}+h y_{n}\left(\left(1-\frac{y_{n}}{c}\right)-\frac{b(1-m) x_{n} y_{n}}{y_{n}+(1-m) x_{n}}-h_{2}\right)=g\left(x_{n}, y_{n}\right)
\end{aligned}
$$

With $x_{n}$ is a prey population density and $y_{n}$ is a predator population density. All parameters are assumed to be positive. $h_{1}$ is the rate of harvesting of prey, $h_{2}$ is the rate of harvesting predators, $m x$ is expressing the rate of the first species to shelter, then the rate of the first species that can be preyed by the second species is $(1-m) x$ by $m \in[0,1)$. While $a, b$ and $c$ is modification result's parameter in [5] and $h$ is the step size

\section{THE EXISTENCE AND STABILITY OF FIXED POINTS}

The discrete dynamic system fixed point is the point $\left(x^{*}, y^{*}\right)$ that meet $f\left(x^{*}, y^{*}\right)=x^{*}$ and $g\left(x^{*}, y^{*}\right)=y^{*}$, that is

$$
x^{*}=x^{*}+h x^{*}\left(\left(1-x^{*}\right)-\frac{a(1-m) x^{*} y^{*}}{y^{*}+(1-m) x^{*}}-h_{1}\right)=f\left(x^{*}, y^{*}\right)
$$

and

$$
y^{*}=y^{*}+h y^{*}\left(\left(1-\frac{y^{*}}{c}\right)-\frac{b(1-m) x^{*} y^{*}}{y^{*}+(1-m) x^{*}}-h_{2}\right)=g\left(x^{*}, y^{*}\right)
$$

from that combination we get 2 fixed points which is:

(i) $E_{1}\left(1-h_{1}, 0\right)$ with existence condition is $h_{1}<1$ namely predator extinction.

(ii) $E_{2}\left(0, c\left(1-h_{2}\right)\right)$ with existence condition is $h_{2}<1$ namely prey extinction.

(iii) $E_{3}\left(x^{*}, y^{*}\right)$ where $y^{*}=\frac{\left(\left(1-x^{*}\right)-h_{1}\right)(1-m) x^{*}}{a(1-m)-\left(\left(1-x^{*}\right)-h_{1}\right)}$ and $x^{*}$ is positive root from equation:

$$
A x^{* 2}+B x^{*}+C=0
$$

with

$A=(1-m)+\frac{b c}{a(1-m)}$

$B=c\left(1-h_{2}\right)+\frac{2 b c}{a(1-m)}\left(a(1-m)-\left(1-h_{1}\right)\right)-(1-$

$\left.h_{1}\right)(1-m)$,

and

$C=c\left(a(1-m)-\left(1-h_{1}\right)\right)\left(\frac{b}{a(1-m)}(a(1-m)-(1-\right.$ $\left.\left.\left.h_{1}\right)\right)+1-h_{2}\right)$, 
$D=B^{2}-4 A C$,

$D=\left(c\left(1-h_{2}\right)-\left(1-h_{1}\right)(1-m)\right)^{2}-4 c(1-m)(a(1-$ $\left.m)-\left(1-h_{1}\right)\right)\left(\left(1-h_{2}\right)+b\right)$.

The solution of this equation is:

$$
x_{1,2}^{*}=\frac{-B \pm \sqrt{D}}{2 A} .
$$

By analyzing sign of $B, C$ and discriminant $D$ the researchers get the cases:

Case 1: If $C<0$, then system (1) has unique interior fixed point

$E_{3,1}=\left(x_{3,1}^{*}, y_{3,1}^{*}\right)=\left(\frac{-B+\sqrt{B^{2}-4 A C}}{2 A}, \frac{\left(\left(1-x^{*}\right)-h_{1}\right)(1-m) x^{*}}{a(1-m)-\left(\left(1-x^{*}\right)-h_{1}\right)}\right)$.

Case 2: If $B<0$ and $D=B^{2}-4 A C=0$, then system (1) has unique interior fixed point

$E_{3,2}=\left(x_{3,2}^{*}, y_{3,2}^{*}\right)=\left(\frac{-B}{2 A}, \frac{\left(\left(1-x^{*}\right)-h_{1}\right)(1-m) x^{*}}{a(1-m)-\left(\left(1-x^{*}\right)-h_{1}\right)}\right)$

Case 3: If $C=0$ and $B<0$, then system (1) has unique interior fixed point

$$
E_{3,3}=\left(x_{3,3}^{*}, y_{3,3}^{*}\right)=\left(\frac{-B}{A}, \frac{\left(\left(1-x^{*}\right)-h_{1}\right)(1-m) x^{*}}{a(1-m)-\left(\left(1-x^{*}\right)-h_{1}\right)}\right)
$$

Case 4: If $B<0, C>0$ and $D=B^{2}-4 A C>0$, then system (1) has two interior fixed points

a. $E_{3,4+}=\left(x_{3,4+}^{*}, y_{3,4+}^{*}\right)=$

$\left(\frac{-B+\sqrt{B^{2}-4 A C}}{2 A}, \frac{\left(\left(1-x^{*}\right)-h_{1}\right)(1-m) x^{*}}{a(1-m)-\left(\left(1-x^{*}\right)-h_{1}\right)}\right)$

b. $E_{3,4-}=\left(x_{3,4-}^{*}, y_{3,4-}^{*}\right)=$

$\left(\frac{-B-\sqrt{B^{2}-4 A C}}{2 A}, \frac{\left(\left(1-x^{*}\right)-h_{1}\right)(1-m) x^{*}}{a(1-m)-\left(\left(1-x^{*}\right)-h_{1}\right)}\right)$.

Case 5 :

If no condition in case 1-4 holds, then system (1) has no positive fixed point.

\section{A. Stability of Fixed Point}

To learn the stability of fixed points of the model, we can see that the system (1) is in 2-dimesion, so that we can use this Lemma [9], which can be easily proved by the relations between roots and coefficients of a quadratic equation

Lemma 1. Let $F(\lambda)=\lambda^{2}-p \lambda+q$. Suppose that $F(1)>$ $0, \lambda_{1}$ and $\lambda_{2}$ are the two roots of $F(\lambda)=0$. Then

1. $\left|\lambda_{1}\right|<1$ and $\left|\lambda_{2}\right|<1$ if and only $F(-1)>0$, and $q<$ 1 ,

2. $\left|\lambda_{1}\right|<1$ and $\left|\lambda_{2}\right|>1$ (or $\left|\lambda_{1}\right|>1$ and $\left|\lambda_{2}\right|<1$ ) if and only if $F(-1)<0$,

3. $\left|\lambda_{1}\right|>1$ and $\left|\lambda_{2}\right|>1$ if and only if $F(-1)>0$, and $q>$ 1 ,

4. $\lambda_{1}$ and $\lambda_{2}$ are complex and $\left|\lambda_{1}\right|=\left|\lambda_{2}\right|=1$ if and only if $p^{2}-4 q<0$ and $q=1$.

Let $\lambda_{1}$ and $\lambda_{2}$ are two eigen values of the fixed points. We recall some definitions of topological types for a fixed point $\left(x^{*}, y^{*}\right)$. The fixed point $\left(x^{*}, y^{*}\right)$ is called a sink if $\left|\lambda_{1}\right|<1$ and $\left|\lambda_{2}\right|<1$. The fixed point $\left(x^{*}, y^{*}\right)$ is called saddle if $\left|\lambda_{1}\right|<1$ and $\left|\lambda_{2}\right|>1$ (or $\left|\lambda_{1}\right|>1$ and $\left|\lambda_{2}\right|<1$ ). The fixed point $\left(x^{*}, y^{*}\right)$ is called source if $\left|\lambda_{1}\right|>1$ and $\left|\lambda_{2}\right|>1$. And $\left(x^{*}, y^{*}\right)$ is called non-hyperbolic if either $\left|\lambda_{1}\right|=1$ or $\left|\lambda_{2}\right|=1$

The Jacobian matrix of system (1) is
$J\left(x^{*}, y^{*}\right)=\left[\begin{array}{cc}1+h-2 h x^{*}-\frac{h a(1-m) y^{\prime 2}}{\left(y^{*}+(1-m) x^{*}\right)^{2}}-h h_{1} & -\frac{h a(1-m)^{2} x^{\prime 2}}{\left(y^{*}+(1-m) x^{*}\right)^{2}} \\ \frac{h b(1-m) y^{\prime 2}}{\left(y^{*}+(1-m) x^{*}\right)^{2}} & 1+h-\frac{2 h y^{*}}{c}+\frac{h b(1-m)^{2} x^{\prime 2}}{\left(y^{*}+(1-m) y^{*}\right)^{2}}-h h_{2}\end{array}\right]$

Jacobian matrix used to analyze stability of each fixed point. The Jacobian matrix in $E_{1}\left(1-h_{1}, 0\right)$ is

$$
J\left(1-h_{1}, 0\right)=\left(\begin{array}{cc}
1-h\left(1+h_{1}\right) & -h a \\
0 & 1+h\left(1+b-h_{2}\right)
\end{array}\right)
$$

The stability type of the fixed point $E_{1}$ is expressed in terms of the following theorem.

Theorem 1. Let $h_{a}=\frac{2}{\left(1+h_{1}\right)}, h_{b}=\frac{2}{-1-b+h_{2}}$, and $h_{2}>1+b$

1. If $<<\min \left(h_{a}, h_{b}\right)$ then $E_{2}$ is a sink

2. If $\left(h_{a}, h_{b}\right)<h<\max \left(h_{a}, h_{b}\right)$ then $E_{1}$ is saddle.

3. If $h>\max \left(h_{a}, h_{b}\right)$ then $E_{2}$ is source.

4. If $h=h_{a}$ or $h=h_{b}$ then $E_{2}$ is non-hyperbolic.

Proof: The Eigen value of Jacobian matrix (2) is $\lambda_{1}=1-$ $h\left(1+h_{1}\right)$ and $\lambda_{2}=1+h\left(1+b-h_{2}\right)$.

1. $E_{1}$ is stable $(\sin k)$ if $-1<1-h\left(1+\mathrm{h}_{1}\right)<1$ and $-1<$ $1+h\left(1+b-h_{2}\right)<1$.

The first condition causes

$$
-2<-h\left(1+h_{1}\right)<1
$$

Which is equivalence with

$$
0<h<\frac{2}{\left(1+h_{1}\right)}=h_{a}
$$

Second condition causes

$$
-2<h\left(-1-b+h_{2}\right)<2,
$$

So that

$$
0<h\left(-1-b+h_{2}\right)<2
$$

Because $h_{2}>1+b$ so it obtains,

$$
0<h<\frac{2}{\left(-1-b+h_{2}\right)}=h_{b} \text {. }
$$

That clear $E_{1}$ is stable $(\sin k)$ if $h<\min \left(h_{a}, h_{b}\right)$.

2. It's clear that $\left|\lambda_{1}\right|<1$ and $\left|\lambda_{2}\right|>1$ (or $\left|\lambda_{1}\right|>1$ and $\left.\left|\lambda_{2}\right|<1\right)$ equivalence with $h>h_{a}$ and $h<h_{b}$ and $h<$ $h_{a}$ and $h>h_{b}$. Therefore $E_{1}$ is unstable saddle (saddle), if $\left(h_{a}, h_{b}\right)<h<\max \left(h_{a}, h_{b}\right)$.

3. It's clear that $E_{0}$ is unstable (source) if $\left|\lambda_{1}\right|>1$ and $\left|\lambda_{2}\right|>1$ that equivalence with $h>\max \left(h_{a}, h_{b}\right)$.

4. It's clear that $E_{1}$ is non-hyperbolic if $\left|\lambda_{1}\right|=\left|\lambda_{2}\right|=1$ that equivalence with $h=h_{a}$ or $h=h_{b}$.

The Jacobian matrix in $E_{1}\left(0, c\left(1-h_{2}\right)\right)$ is

$$
J\left(0, c\left(1-h_{2}\right)\right)=\left(\begin{array}{cc}
1+h\left(1-h_{1}\right)-h a(1-m) & 0 \\
h b(1-m) & 1-h\left(1-h_{2}\right)
\end{array}\right)
$$

The stability type of the fixed point $E_{2}$ is expressed in terms of the following theorem.

Theorem 2 Let $h_{c}=\frac{2}{\left(a(1-m)-\left(1-h_{1}\right)\right)}, \quad h_{d}=\frac{2}{1-h_{2}}, \quad$ and $a(1-m)>\left(1-h_{1}\right)$

1. If $h<\min \left(h_{c}, h_{d}\right)$ then $E_{2}$ is a sink.

2. If $\left(h_{c}, h_{d}\right)<h<\max \left(h_{c}, h_{d}\right)$ then $E_{2}$ is a saddle.

3. If $h>\max \left(h_{c}, h_{d}\right)$ then $E_{2}$ is a source

4. If $h=h_{a}$ or $h=h_{d}$ then $E_{2}$ is a non-hyperbolic.

The Jacobian matrix in fixed point $E_{3}\left(x^{*}, y^{*}\right)$ is 


$$
J\left(x^{*}, y^{*}\right)=\left(\begin{array}{cc}
1-h x^{*} & -\frac{h a(1-m)^{2} x^{* 2}}{\left(y^{*}+(1-m) x^{*}\right)^{2}} \\
-\frac{h b(1-m)^{2} y^{* 2}}{\left(y^{*}+(1-m) x^{*}\right)^{2}} & 1-\frac{h y^{*}}{c}
\end{array}\right)
$$

Let $B_{0}=\frac{x^{*} y^{*}}{c}+\frac{a b(1-m)^{3} x^{* 2} y^{* 2}}{\left(y^{*}+(1-m) x^{*}\right)^{4}}, B^{*}=\frac{1}{4}\left(x^{*}+\frac{y^{*}}{c}\right)^{2}$ and

$h^{*}=\frac{x^{*} c^{2}\left(y^{*}+(1-m) x^{*}\right)^{4}+c y^{*}\left(y^{*}+(1-m) x^{*}\right)^{4}}{c x^{*} y^{*}\left(y^{*}+(1-m) x^{*}\right)^{4}+c a b(1-m)^{3} x^{* 2} y^{* 2}}$,

$R=\frac{x^{*} y^{*}}{c}+\frac{a b(1-m) x^{* 2} y^{* 2}}{\left(y^{*}+(1-m) x^{*}\right)^{4}}, S=-2\left(x^{*}+\frac{y^{*}}{c}\right)$.

$T=4, h_{e}=-\frac{S}{2 R}-\frac{\sqrt{S^{2}-4 R T}}{2 R}=h^{*}-\frac{\sqrt{S^{2}-4 R T}}{2 R}$,

and

$h_{f}=\frac{-S}{2 R}+\frac{\sqrt{S^{2}-4 R T}}{2 R}=h^{*}+\frac{\sqrt{S^{2}-4 R T}}{2 R}$ then

1. Interior fixed point $\left(x^{*}, y^{*}\right)$ in case 1,3 and $4(a)$ is a sink if $1-m>0$ and one of the following conditions holds.

(a). $0<h<h^{*}$ and $B_{0} \geq B^{*}$, or

(b). $0<h<h_{e}$ and $B_{0}<B^{*}$.

2. Interior fixed point $\left(x^{*}, y^{*}\right)$ case 1,3 and $4(a)$ is a saddle if $1-m>0, h_{e}<h<h_{f}$ and $B_{0}<B^{*}$

3.Interior fixed point $\left(x^{*}, y^{*}\right)$ in case 1,3 and $4(a)$ is a source if $1-m>0$ and one of the following conditions holds.

(a). $h>h^{*}$ and $B_{0} \geq B^{*}$, or

(b). $h>h_{f}$ and $B_{0}<B^{*}$.

4. Interior fixed point $\left(x^{*}, y^{*}\right)$ in case 1,3 and $4(a)$ is a nonhyperbolic if $1-m>0$ and one of the following conditions holds.

(a). $h=h^{*}$ and $B_{0} \geq B^{*}$, or

(b). $h=h_{e}$ or $h=h_{f}$ and $B_{0}<B^{*}$.

\section{NUMERICAL SIMULATION}

This simulation is done to illustrate the existence of $E_{1}$ and $E_{3}$ by using parameter $a=1.8, b=0.1, c=0.2, m=$ $0.6, h_{1}=0.4$ and $h_{2}=1.2$. Based on these parameters the fixed point is generated into $E_{1}=(0.60)$, and fixed point $E_{3}=(0.3854,0.0655)$. This simulation generates $h_{a}=$ $1.4286, h_{b}=20$. So, according to the previous analysis, it can be concluded that the fixed point $E_{1}$ will be (1) Sink if $h<1.4286$, (2) Saddle if $1.4286<h<20$.(3) Source if $h>20$.(4) Non-hyperbolic if $h=1.4286$ and $h=20$. To demonstrate the suitability between numerical simulation and the results of the analysis, a step size $h=0.1$ was obtained and a simulation result is shown in Fig. 1 below.

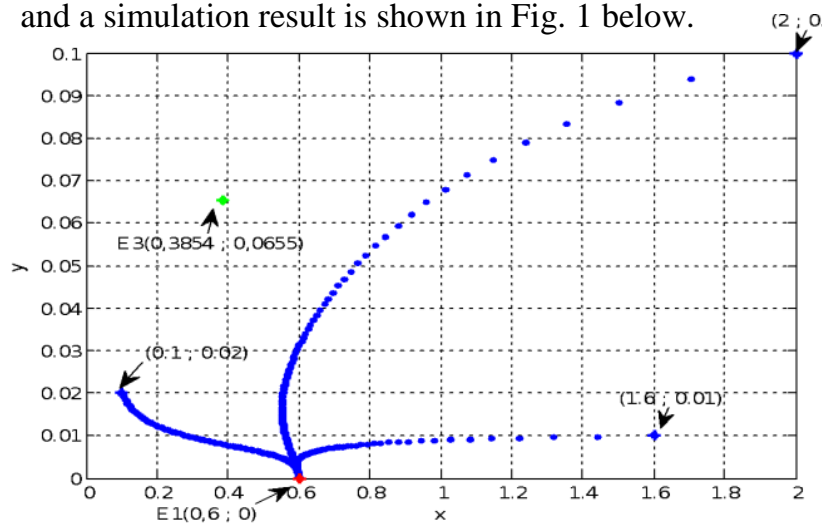

Fig. 1. The model simulation for stability of fixed point $E_{1}$
In the Fig. 1, it appears that with some initial values almost the solution converges for $E_{1}$. This is in accordance with the results of the analysis which states that the fixed point $E_{1}$ sink if $h<1.4286$. Next, in Fig. 2 it will be simulated stability of fixed point $E_{2}$ with parameter values $a=1.8, b=1.2, c=$ $0.2, m=0.6$, dan $h_{1}=h_{2}=0.4$.

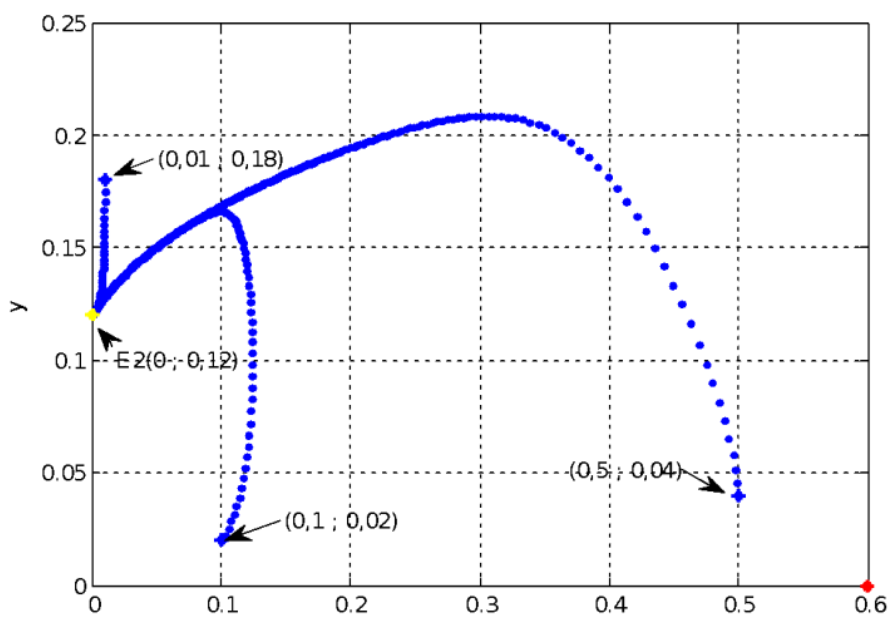

Fig. 2. The model simulation for stability of fixed point $E_{2}$

The third simulation uses parameters $a=1, b=1, c=$ $0.2, m=0.6, h_{1}=0.6$, and $h_{2}=0.4$.

Based on these parameters the fixed point is generated $E_{3}(0.04,0.142)$ is sink. Fixed point $E_{1}(0,0.12)$ and $E_{2}(0.4,0)$ exist but not stable. The third simulation illustrate in Fig. 3.

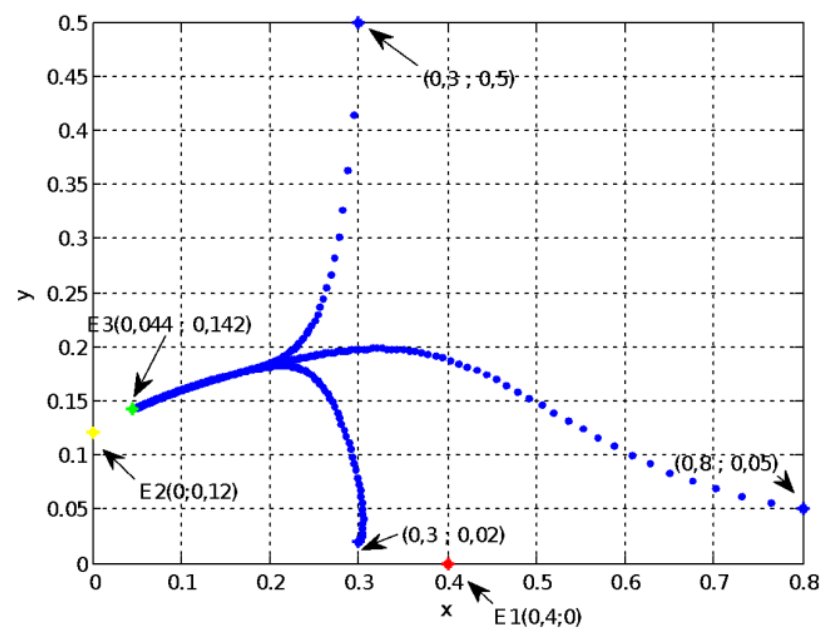

Fig. 3. The model simulation for stability of fixed point $E_{3}$

The Fig. 3 shows that by using some convergent initial values toward an interior fixed point $\left(x^{*}, y^{*}\right)$ that satisfies cases 1,3 and 4 (a). This means that the interior fixed points $\left(x^{*}, y^{*}\right)$ that meet cases 1, 3 and 4 (a) are stable. This shows that in the long run, with the above parameters, the two ecosystems will be balanced

\section{DISCUSSION AND CONCLUSION}

The predator-prey model was obtained by discretizing the model using the Euler method approach. The results of the analysis show that the predator-prey model has three fixed points, i.e. the fixed point of the predator extinction point $E_{1}$, 
the prey extinction point $E_{2}$ and the fixed point of the interior $E_{3}$. The nature of the stability of the fixed point $E_{1}, E_{2}$ and $E_{3}$ determined by a certain terms and conditions.

\section{REFERENCES}

[1] M. A. Aziz-Alaoui and M. D. Okiye, "Boundedness and global stability for a predator-prey model with modified Leslie-Gower and Holling-type II schemes,” Appl. Math. Lett., vol. 16, pp. 1069-1075, 2003.

[2] H. Guo and X. Song, "An impulsive predator-prey system with modified Leslie-Gower and Holling type II schemes," Chaos, Solitons and Fractals, vol. 36, pp. 1320-1331, 2008.

[3] P. H. Leslie and J. C. Gower, "The properties of a stochastic model for the predator-prey type of interaction between two species," Biometrika, vol. 47, pp. 219-234, 1960.
[4] P. Lenzini and J. Rebaza, "Nonconstant Predator Harvesting on RatioDependent Predator-prey models.” J. Appl. Math. Sci., vol. 4, pp. 791$803,2010$.

[5] N. N. Ilmiyah, Trisilowati and A. R. Al Ghofari, "Dynamical Analysis of a Harvested Predator-prey Model with Ratio-dependent Response Function and Prey Refuge," Appl. Math. Sci., vol. 8, pp. 5027-5037, 2014.

[6] T. K. Kar, "Modelling and Analysis of a Harvested Pre-predator System Incorporating a Prey Refuge," J. Comput. and Appl. Math., vol. 185, pp. 19-33, 2006

[7] W. Z. Jie, Xi-Sheng, Z. Xian-He, and G. Hong-Liang, "Stability and Hopf Bifurcation Analysis on a Numerical Discretization of the Distributed Delay Equation,” Chin. Phys. Lett., vol. 29, 2011.

[8] A. Suryanto, "A Dynamically Consistent Nonstandard Numerical Scheme For Epidemic Model With Modified Saturated Incidate Rate," Int. J. Math. and Comput., vol. 13, no. D11, pp. 112-113, 2011.

[9] L. Xiaoli L and D. Xiao, "Complex Dynamic Behaviors of a Discretetime Predator-Prey System," Chaos, Solitons and Fractals, vol. 32, pp. $80-94$ 